\title{
Considerações Sobre o Conceito de Ambiente e os Desafios Tecnológicos para Reflexões em Educação Ambiental
}

\author{
Consideraciones Sobre el Concepto de Medio Ambiente y los Desafíos \\ Tecnológicos para laRreflexión en la Educación Ambiental \\ Considerations on the Concept of Environment and the Technological \\ Challenges for Reflections in Environmental Education
}

\author{
Me. Samuel Lopes Pinheiro ${ }^{1}$
}

\begin{abstract}
Resumo
O trabalho a seguir trata de uma reflexão a partir do encontro de horizontes, o da Educação Ambiental e o de se pensar os desafios das sociedades tecnológicas. Para isso, parte da pergunta sobre quais os diferentes entendimentos de ambiente, para o tratamento do conceito de "ambiente" em Sociologia Ambiental e se aventura na aproximação com a literatura de Henry Thoreau como forma de contextualizar o surgimento dos significados que ambiente pôde representar ao longo do século XX e após o seu consequente encontro com o ambiente tecnológico do início do século XXI. A partir disso, discute-se sobre discursos tecnológicos, como a questão de uma possível convergência entre tecnologia e ecologia e os seus desafios culturais e educativos. Embora valha-se da literatura e ilustrações do século XIX para refletir sobre o ambiente, não deixa de dissociar-se do tempo presente ao pontuar aspectos de crises civilizatórias da atualidade, ao destacar as injustiças ambientais que muitas vezes são exacerbadas com a aceleração tecnológica. Os aspectos interdisciplinar e a inspiração da metodologia transdisciplinar, de buscar ir além das próprias disciplinas são fundamentais na constituição desse diálogo de saberes que não pretende se esgotar aqui, mas apenas ser um ponto de partida para outras reflexões.
\end{abstract}

Palavras-chave: Ambiente; Desafios tecnológicos; Educação Ambiental; Interdisciplinaridade; Transdisciplinaridade

\section{Resumén}

El siguiente texto trata de una reflexión a partir del encuentro de horizontes, la de la Educación Ambiental y la de la sobre los retos de las sociedades tecnológicas. Para esto, se parte de la pregunta de cuáles son las diferentes comprensiones del ambiente, para el tratamiento del concepto de "ambiente" en la Sociología Ambiental y se incursiona en el acercamiento con la literatura de Henry Thoreau como una forma de contextualizar el surgimiento de los significados que el medio ambiente podría representar a lo largo del siglo XX y tras su consecuente encuentro con el entorno tecnológico de principios del siglo XXI. A partir de esto, discutimos los discursos tecnológicos, como la cuestión de una posible convergencia entre la tecnología y la ecología y sus desafíos culturales y educativos. Aunque utiliza la literatura y las ilustraciones del siglo XIX para reflexionar sobre el medio ambiente, no deja de disociarse de la actualidad puntualizando aspectos de las actuales crisis civilizatorias, poniendo de relieve las injusticias ambientales que a menudo se ven exacerbadas por la aceleración tecnológica. Los aspectos interdisciplinarios y la inspiración de la metodología transdisciplinaria, de buscar ir más allá de las disciplinas mismas, son fundamentales en la constitución de este diálogo de saberes que no pretende agotarse aquí, sino sólo ser un punto de partida para otras reflexiones.

Palabras clave: Ambiente; Desafio tecnológicos; Educación ambiental; Interdisciplinariedad; Transdisciplinaridad.

\footnotetext{
${ }^{1}$ Doutorando em Educação Ambiental; Universidade Federal do Rio Grande - FURG; Rio Grande, Rio Grande do Sul, Brasil; samuelshankara@gmail.com
} 


\begin{abstract}
The following work deals with a reflection from the meeting of horizons, that of Environmental Education and that of thinking about the challenges of technological societies. For this, it starts from the question about the different understandings of environment, for the treatment of the concept of "environment" in Environmental Sociology and to venture into the approach with the literature of Henry Thoreau as a way of contextualizing the emergence of the meanings that environment could represent throughout the twentieth century and after its consequent encounter with the technological environment of the early twenty-first century. From this, we discuss technological discourses, such as the issue of a possible convergence between technology and ecology and its cultural and educational challenges. Although it uses 19th century literature and illustrations to reflect on the environment, it does not fail to dissociate itself from the present time by punctuating aspects of today's civilizing crises, by highlighting environmental injustices that are often exacerbated by technological acceleration. The interdisciplinary aspects and the inspiration of the transdisciplinary methodology, of seeking to go beyond the disciplines themselves, are fundamental in the constitution of this dialogue of knowledge that does not intend to be exhausted here, but only to be a starting point for other reflections.
\end{abstract}

Keywords: Environment; Technological Challenges; Environmental Education; Interdisciplinarity; Transdisciplinarity.

\title{
1. Considerações iniciais
}

O leitor encontrará nas seguintes páginas, um trabalho que tem muito mais um caráter de ensaio, que propõe reflexões no e com o campo da Educação Ambiental, do que um trabalho em forma de artigo com uma pesquisa que proponha resultados fechados a partir de métodos de análises de materiais empíricos ou de revisões de resultados já formulados. O contexto dessas reflexões é o das múltiplas crises que se exacerbam ou que se evidenciaram ainda mais com o advento da crise sanitária desencadeada em escala global em 2019-2020, e o paralelo disso com a questão da intensificação dos usos tecnológicos no aprender, ensinar e se relacionar.

O texto se arrisca em lidar com referências que podem ser consideradas oriundas de solos epistemológicos distintos, como ao cruzar literatura, sociologia e ilustrações. Para o diálogo entre diferentes campos, fundamenta-se na metodologia transdisciplinar que propõe uma abertura dialógica e o rigor para a reflexão. Há um trânsito em autores da literatura, como Henry Thoreau, que embora bem carregado de uma visão um tanto quanto idealizada de natureza, seus escritos são responsáveis em inspirar muito do que veio a se constituir enquanto Educação Ambiental a partir dos anos de 1960. Igualmente, transita por autores da sociologia, como o canadense John Hannigan que prioriza um enfoque em Sociologia Ambiental e o francês Edgar Morin, que argumenta em favor de um pensamento transdisciplinar e da realização do complexus, daquilo que é tecido conjuntamente. No campo da educação a orientação que fundamenta é novamente os aportes complexos do autor Edgar Morin, mas também a presença de Paulo Freire com sua criticidade e dialogicidade e, Danilo Streck e Telmo Adams, estudiosos de Paulo Freire. Para compor as reflexões em termos de tecnologia, trazemos autores como Bruno Bachimont e Bernard Stigler, autores estudados a partir do grupo 
de estudos $\mathrm{COSTECH}^{2}$ na França, bem como uma análise de um texto francês sobre aceleração tecnológica e ecologia promovido por organismos como a WWF.

De acordo com Nicolescu (2019) a metodologia transdisciplinar é fundamentada em três pressupostos: o ontológico, o lógico e o epistemológico. Há na natureza e no nosso conhecimento de natureza, diferentes níveis de realidade do objeto e do sujeito. A lógica é assegurada pela lógica do meio incluído, que tenta sair do binarismo da lógica clássica. E o pressuposto epistemológico é amparado pelo pensamento complexo em Edgar Morin (2016), que faz o convite a partirmos da dúvida da dúvida e a transitar pelas incertezas. A investigação transdisciplinar não exclui o próprio ser do investigador, pois a subjetividade está manifesta e não escondida. Dessa forma, a reflexão que se segue busca transitar de forma transdisciplinar entre diferentes discussões e autores, mantendo uma abertura ao diálogo, ao mesmo tempo que o rigor em complexificar os pontos de contato e debate aqui elencados.

\section{Discursos de Ambiente e um Breve Histórico da Educação Ambiental}

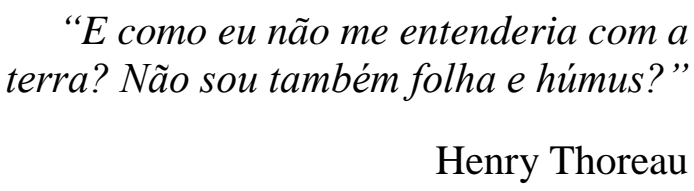

A escolha de Thoreau como epígrafe se dá pelo fato de que livros como "Walden ou a vida nos bosques" (1854), e "Desobediência Civil" (1849) deste autor, foram marcos da produção literária ocidental no século XIX e que ao longo do século XX reverberaram nos movimentos contraculturais de 1960, momento de grande fertilidade de ideias e de concepções ecológicas que diretamente se ligam ao surgimento da Educação Ambiental, como bem lembrado por Isabel Carvalho que diz que o período foi marcado pela "contestação a sociedade consumista e materialista, tendo como horizonte utópico uma vida livre das normalizações e repressões sociais e em harmonia com a natureza" (CARVALHO, 2012, p.46). Além também de Thoreau ser comumente associado a figuras de propagadores de ideais pacifistas como Gandhi, na Índia e Martin Luther King nos Estados Unidos e à construção do imaginário e representação de natureza, bem como às próprias lutas ambientalistas, que são forças muito vivas na sociedade contemporânea.

\footnotetext{
${ }^{2}$ Costech (EA2223) - Connaissance Organisation et Systèmes TECHniques - é o laboratório de investigação do Departamento de Tecnologia e Ciências Humanas da Université de Technologie de Compiègne (UTC). A unidade de investigação Costech é uma equipa multidisciplinar de investigadores que trabalham na relação entre Homem / Tecnologia / Sociedade. Mais informações em: http://www.costech.utc.fr/
} 
Thoreau estava em busca pela "essência da vida" e para isso queria compreender o que era o viver. Em suas palavras: "queria viver profundamente e sugar a vida até a medula" (2019, p.95). Ele experimentou a simplicidade em meio a uma natureza exuberante, em uma cabana próximo às margens do lago Walden, em Massachussets, nos EUA. A sua busca pela compreensão de si, temática presente em sua obra, é um tema universal que atravessa os seres humanos de diferentes épocas e que se funde a uma complexa rede de significados e necessidades propostas pelas diversas crises que a humanidade de hoje enfrenta. A busca daquele Thoreau, pode representar também a busca de cada indivíduo e que se soma às buscas que fazemos enquanto sociedade. Obviamente, temos de alargar o horizonte daquele ser humano do século XIX encarnado por Thoreau, levar em consideração sua insatisfação com a crescente industrialização e mecanização do trabalho, atualizando-o com a história do século XX e inícios do XXI, bem como os processos de industrialização que já passou por diferentes etapas; a globalização econômica alcançou um novo patamar; as novas tecnologias operam uma aceleração das trocas e de informação nunca antes vistas e a "cultura de massas" também atua nos modos e sentidos de ser através das orientações de gostos e demandas de consumo, assim como os modos de produção e de geração de necessidades.

Poderíamos classificar a literatura de Thoreau e sua compreensão de natureza, como sendo a representação de uma visão arcádica de natureza de acordo com as proposições de discursos ambientais feitas pelo sociólogo John Hannigan. O autor canadense, Hannigan (2009) apresenta a sua própria classificação para os discursos de ambiente que se deram ao longo do século XX. Seriam eles: o arcádico, o do ecossistema e o da justiça. No primeiro deles podemos elencar alguns elementos como a natureza tratada sem preço de valor estético e espiritual, há um movimento de volta à natureza e uma aliança de preservadores e conservacionistas. No segundo discurso, há a ideia de que a interferência humana perturba o equilíbrio das comunidades bióticas, tem como lugar primário de ebulição as ciências biológicas e uma fusão entre ecologia e ética. No terceiro discurso, o de justiça, teríamos a ideia de que todos os cidadãos têm o direito básico de viver e trabalhar em um ambiente saudável e há uma fusão de direitos civis e de ambientalismo.

Se tomássemos as classificações teóricas como nomenclaturas estanques que não se modificam ao longo dos tempos, ou que estão fechadas em suas esferas de atuação nominal, poderíamos rechaçar de imediato os escritos de Thoreau diante da compreensão contemporânea de ambiente e natureza, devido a suas características um tanto idealistas ou romantizadas da natureza. No entanto, a leitura de seus livros impulsionou ou, de certa maneira, fez parte de um ideário ecológico e ambientalista em tempo posterior ao seu e que reverbera ainda hoje. Assim 
poderíamos complexificar a classificação de John Hannigan para uma proposição retroativa entre as próprias categorias, em que uma forma de discurso pode reverberar no outro e ainda em um terceiro. Pois, a nosso ver, uma compreensão de ambiente enquanto carregado de um discurso de justiça, também passa ou carrega elementos dos discursos temporais anteriores como o ecossistêmico e o arcádico, e que para Hannigan estão mais subordinados a um determinado período histórico. Isso pode ser muito significativo enquanto movimento de pesquisa, o de fazer o exercício de retomarmos a literatura inspiradora de autores e pensadores do século XX que se dedicaram a convergir sua preocupação política e filosófica ao olhar da Educação Ambiental.

Dirige teu olhar para dentro de ti, E mil regiões encontrarás ali, Ainda ignotas. Percorre tal via E mestre serás em tua cosmografia (THOREAU, 2019, p.303).

Embora o nosso tempo presente esteja ainda mais distante do tempo de Thoreau, algumas de suas inquietações como a busca pela "compreensão sobre si" continua atual porque ela é uma das perguntas fundantes da condição humana, a de se questionar sobre o mundo e sobre si mesmo. Neste trecho acima, a provocação da literatura é dizer-nos que o exercício do se conhecer é infindável, mas é valioso segui-lo mesmo em sua adversidade porque enriquece e complexifica sua relação humana no mundo. Neste exercício de inquietação constante sobre a relação ser humano e natureza, sobre o eu e o mundo encontramos correspondência com os fundamentos da Educação Ambiental, porque há aí um questionar sobre o que é o exercício do ensinar e sobre o quê ensinar. O ensinar e aprender sobre a condição humana e sobre sua complexidade no mundo.

Nem sempre essa percepção da relação humano e natureza esteve presente nos discursos de Educação Ambiental. Pois quando de seu surgimento, a Educação Ambiental é marcada por uma visão naturalista, que era muito forte nos anos de 1960 e 1970, essa visão traz um pouco um aspecto de posicionar ser humano como algo diferente da natureza. Assim, superar essa marca, mediante a afirmação de uma visão socioambiental, exigiu e ainda exige um esforço de superação da dicotomia entre sociedade e natureza, para poder ver as relações de interação permanente entre a vida humana social e a vida biológica da natureza (CARVALHO, 2012).

A terminologia de socioambiental só foi se fortalecer durante os anos de $1990 \mathrm{em}$ especial com a realização da conferência Eco 92 no Rio de Janeiro. Embora essa terminologia 
continue atual e desafiadora, os anos iniciais do século XXI foram marcados por outras nomenclaturas, como a ideia de sustentabilidade e desenvolvimento sustentável que são enormemente questionáveis quando de sua efetivação prática e política. Isto devido ao caráter de manutenção ou fortalecimento do neoliberalismo em alguns casos como a implementação de medidas esverdeantes em diversos setores da sociedade.

Partimos do reconhecimento da existência de uma crise da Educação que atravessa diferentes níveis de realidade e expresões da sociedade. Ideia esta verificada em autores como o sociólogo e filósofo Edgar Morin (2020), ao nos informar como uma "crise multidimensional" pode estar presente em muitos termos de forma simultânea. Como uma crise da educação que não está fechada em si, mas está conectada à crise de democracia, crise ética, crise econômica e outras tantas que se interconectam.

Diante desta espiral de crises que se alimentam de uma e outra parte, temos o campo da Educação, que por sua vez é alimentado e alimenta as demais crises e, mais especificamente, temos o campo da Educação Ambiental, que projeta uma atenção maior para com o termo "Ambiental” em suas buscas pedagógicas e em seu fundamentos teórico-práticos. Pois, de acordo com Loureiro (2009) temos que dentre muitas das ideias-força colocados em evento internacional de Educação Ambiental realizado em 1977 na cidade de Tibilisi, está a ideia de ambiente como uma totalidade. Ou seja, em seus aspectos naturais e criados pelo ser humano em uma dinâmica relacional.

A abordagem transdisciplinar, a partir de uma metodologia transdisciplinar que evidencia-se com o pensamento complexo, reconhece uma emergência na criação de um ensino preparado para enfrentar as incertezas, as incompreensões, os erros e as ilusões, desafiando-se na grande missão educativa que é o "ensinar a viver" nos termos colocados por Edgar Morin (2015). E que somado à Educação Ambiental, o desafio torna-se ainda maior, pois temos o “ensinar a viver” articulado com a dimensão ambiental, que também é amplo, pois é estendível nas suas mais diversas acepções, como a de ambiente externo, do chamado meio ambiente ou natureza externa, mas como também a do ambiente interior, do aspecto interno da psiquê e da saúde deste ser humano que não está desvinculado do mundo. Ambientes interno e externo são um e dois ao mesmo tempo, necessários de serem compreendidos juntos e separados, alargando a compreensão daquilo que os une e daquilo que os separa. Ou seja, religação do conhecimento do mundo com o autoconhecimento e de autoconhecimento com conhecimento do mundo. 


\section{Sociedades Tecnológicas e Educação Ambiental}

As ilustrações que se seguem, do francês Jean Marc Cote, na virada do século XIX para o XX, faziam elucubrações de como seria a sociedade no ano 2000. São mais de 80 ilustrações, que foram publicizadas em anos diferentes e que hoje se encontram disponíveis na Biblioteca Nacional Francesa em Paris. A escolha dessas duas se dá justamente porque elas em muito acertaram como a tecnologia se tornou presente hoje. Na primeira delas, dispositivos de comunicação audiovisual ao alcance das mãos, e na segunda, é retratado uma sala de aula, em que a informação dos livros é transmitida via um aparelho que vai à cabeça dos estudantes. Essas duas ilustrações se tornaram reais hoje, pois nos comunicamos instantaneamente via dispositivos móveis e também estudamos, aprendemos e nos informamos por podcasts, audiolivros, ferramentas de educação a distância e outros. Toda uma novidade de ferramentas e dispositivos no terreno da educação.

O intuito deste texto não trata de prender-se a elucubrações quanto ao futuro tecnológico que se intensifica e acelera dia após dia. Mas sim a provocação à reflexão, a partir de aportes metodológicos da complexidade e da Transdisciplinaridade, acerca de um dos grandes desafios contemporâneos, aquele do enorme fluxo de informações e conhecimentos na era das relações virtuais, que direta ou indiretamente associa-se ao desafio da formação dos sujeitos-aprendentes e de sua subjetividade e no que isso diz respeito à Educação Ambiental.

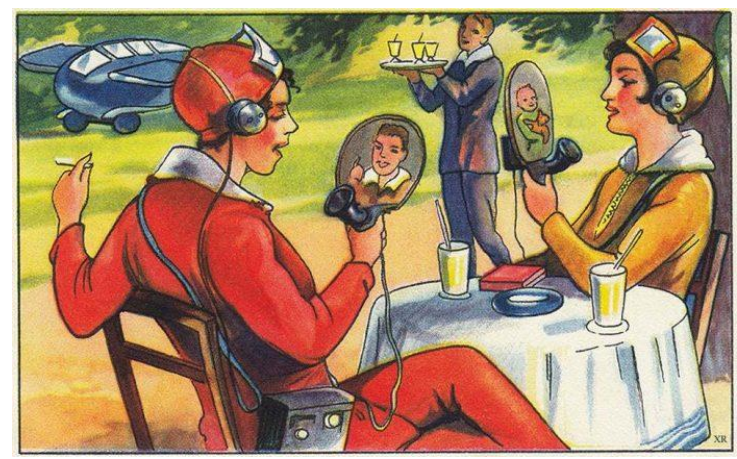

Figura 1- Ilustração de Jean Marc Cote de 1899.

Fonte: Google 


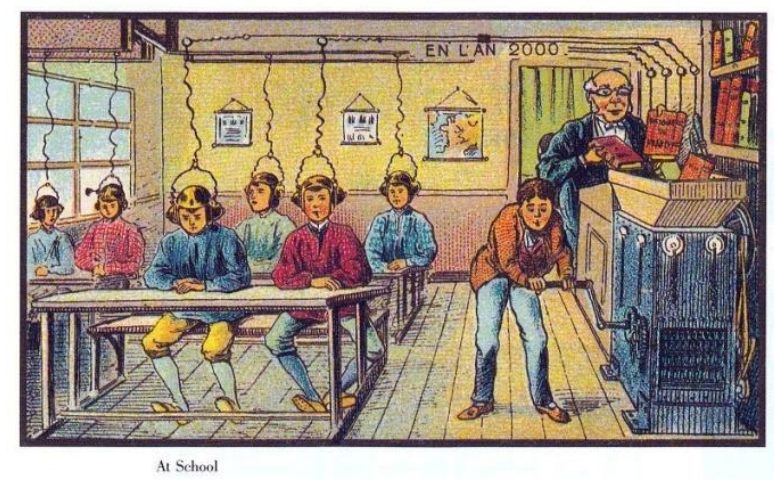

Figura 2- Ilustração de Jean Marc Cote de 1899.

Fonte: Google

Embora abundante em quantidade, a informação neste novo ambiente tecnológico, por vezes, se perde em sua própria mensagem, como é o caso dos atuais discursos socioambientais, que é nossa preocupação aqui. Dessa forma, há caminhos que se cruzam neste texto, o de uma trajetória histórica de um ecologismo e ambientalismo com o advento de uma sociedade tecnológica cada vez mais interconectada. As inúmeras redes de comunicação virtual, propagam mensagens em forma de texto ou de imagem e texto com os mais variados discursos sobre natureza e de uma determinada compreensão de relação sociedade-natureza ou ser humano e natureza. Notícias falsas, verdadeiras, de cunho romântico, transcendentais, distorcidas, científicas, religiosas, etc. A mensagem nunca é neutra, ela é repleta de intencionalidades e quer convencer alguém sobre algo. Poderíamos dizer que muitos dos discursos de natureza na era das redes sociais atravessam uma ou mais daquelas classificações de discursos de ambiente elencados por Hannighan na primeira seção. Pensar-se um sujeito em formação que almeja um pensamento socioambientalmente orientado frente a este cenário de informações é desafiador, para dizer o mínimo.

Para tratarmos a partir da sensação das incertezas do tempo presente, temos por exemplo, a atual crise da pandemia de Coronavirus no mundo desencadeada no ano de 2020. Ela nos faz acordar que uma crise sanitária pode estar conectada a um sentido de policrise como é muito bem colocado por Edgar Morin (2020). A crise é sanitária, mas ao mesmo tempo ela é financeira, social, ecológica, política, educativa, etc. Assim, acredito que é a partir deste ensinamento primordial, que a Educação Ambiental enquanto campo de atuação e reflexão depara-se com a questão da interdependência entre os diferentes conhecimentos e a eventual necessidade de pôr suas visões compartimentadas em diálogo. O desafio, todavia vigente está em como estimular uma passagem para uma relação solidária entre os diferentes domínios do 
conhecimento para que a política não seja ela mesma outro vírus tão mortal ou mais que este que enfrentamos.

Neste sentido, a pandemia exacerba as diferenças estruturais postas nas sociedades ao redor do planeta, agravando ainda mais as injustiças ambientais que já estavam presentes, mas que agora tomam outra visibilidade. Se todas as crises estão interligadas umas às outras, parece que o aprofundamento de uma corrobora com o aprofundamento de outras. Assim, voltamos uma vez mais na questão de como transformar esse círculo vicioso de crises? Um dos caminhos de trabalho que acredito possa continuar se configurando como necessário é o da pesquisa interdisciplinar e transdisciplinar, pois cada vez mais nos damos conta da necessidade da comunicação e do diálogo entre os diferentes domínios do conhecimento.

\begin{abstract}
A interdisciplinaridade, nesse sentido e enquanto pressuposto da Educação Ambiental, não é um princípio epistemológico para legitimar determinados saberes e relações de poder hierarquizadas entre as ciências, nem um método único para a articulação de objetos de conhecimentos, capaz de produzir uma "metaciência". É uma prática intersubjetiva que associa conhecimentos científicos e não científicos e relaciona o racional com o cognitivo, o cognitivo com o sensorial, buscando a construção de objetos de conhecimentos que se abram para novas concepções e compreensões do mundo (natural estrito senso e histórico) e para a construção do sujeito integral. Portanto, esta se traduz como um trabalho coletivo que envolve conteúdos, disciplinas e a própria organização da escola e das ações não formais (relações de poder, modo de gestão, definição do projeto político-pedagógico etc.) (LOUREIRO, 2009, p76).
\end{abstract}

Uma das maneiras que esta visibilidade das injustiças ambientais se torna concreta é precisamente via comunicação virtual das novas tecnologias digitais através dos ambientes virtuais de trocas e plataformas de discussão. Se por um lado a mensagem transmitida é errônea e distorcida, como é o caso do fenômeno das fake news, por outro, o grande fluxo de informações gera configurações inéditas das dinâmicas sociais por meio desta atual cultura política do virtual. A partir de Mota Leite (2019) temos alguns exemplos fartamente citados como: as eleições presidenciais nos EUA, em 2016, que elegeu Donald Trump; o Movimento do Brexit (Movimento de saída do Reino Unido da União Europeia), também em 2016; e as eleições presidenciais no Brasil, em 2018, que elegeu Jair Messias Bolsonaro. Em todos esses casos, o uso de Fake News e de campanhas difamatórias contra pessoas e instituições provocou verdadeiras guerras de opinião, acirramentos ideológicos, polarização política e, sobretudo, desinformação. Com tudo isto, o populismo, os discursos de ódio, a violência física e psicológica, a intolerância, ganharam cores destacadas, pintaram um quadro de retrocesso civilizatório. Os reflexos dessa involução da razão seguem fazendo vítimas em todo o mundo.

A partir disso temos uma democracia em efervescência por conta de todas estas interações de gostos, desgostos, opiniões, argumentos, etc. Todo um novo campo de pesquisa 
emerge disso, desse novo ambiente de encontro que é o virtual e nisso destacamos a importância de laboratórios de pesquisa como é o caso do Costech na França, que de maneira interdisciplinar tece pesquisas em temas transversais que perpassam questões como a relação conhecimento, sociedade e tecnologia.

\section{Discursos Tecnológicos e o Encontro com os Discursos Ambientais}

De acordo com o glossário TransNum apresentado em reunião do Costech, temos a marcação sobre pensar no digital (numerique) não apenas como um meio, mas como nosso meio (e, em particular, como um novo meio de escrita). Isso implica considerar o digital (numerique) como o que está ao nosso redor, mas também entre nós, de acordo com o agir e se transformar em um relacionamento permanente de co-constituição.

Ainda temos a apresentação das ferramentas conceituais que passam por uma entrada através da escrita; o conceito de millieu (de meio como lugar); e ainda o de alfabetização. Dando continuidade a esse entendimento, temos que: "Para desenvolver a alfabetização digital (em nível educacional e científico), a discussão apresenta o conceito de "ambiente ", e mais particularmente o de" ambiente digital ", como uma ferramenta para pensar sobre o que é necessário ensinar para treinar verdadeiros literatos digitais capazes não apenas de usar ferramentas de escrita digital, mas também de entender como elas influenciam nossas maneiras de construir conhecimento e agir em relação aos outros. Lembrando que embora em português apareça a palavra digital, em francês ela está como numerique.

Para contemplar essa busca por compreensão da aproximação de discursos de ambiente oriundos de um pensamento sociológico ambiental e de ambiente em numerique, cheguei na leitura do material francês do Livre Blanc Numerique et Environment ${ }^{3}$ de 2018. Este material é marcado por um apelo a uma convergência de interesses entre a aceleração do numerique 4 com as questões ecológicas. O convite daquele texto é de que ao acelerarmos um, estaríamos acelerando também o outro processo. Em seu início, já coloca que a transição ecológica é um

\footnotetext{
${ }^{3}$ Este material de 2018 é feito por uma equipe de trabalho composta por: Damien Demailly, Mathieu Saujot (Iddri), Renaud Francou, Daniel Kaplan, Jacques François Marchandise (FING), Marine Braud, Aurélie Pontal (WWF France), Frédéric Bordage (GreenIT.fr), François Levin et Jan Krewer (CNNum). E está disponível em diferentes endereços, tais como: https://www.wwf.fr/vous-informer/actualites/livre-blanc-numerique-environnement; ou ainda: https://www.iddri.org/fr/publications-et-evenements/rapport/livre-blanc-numerique-et-environnement

${ }^{4}$ Em português não encontro uma tradução apropriada para fazer a devida diferenciação que se quer fazer no francês entre a palavra "digital" e "numerique". A princípio parece que em ambos os casos a expressão seria traduzida para "digital" em português. No entanto, ao acompanhar palestra de Bernard Stiegler, no Instituto Católico de Paris em 02/03/2020, ele diz preferir o uso do termo numerique, pois numerique comporta um estado de gramatização e uma abertura ao mistério, enquanto que digital é possível de associar a toda técnica, pois esta refere-se a palavra "dedo", e toda técnica seria em sua origem manual.
} 
horizonte inevitável ou um objetivo ao ser alcançado, mas com caminho difícil de ser traçado e a transição numerique é como uma força transformadora de nosso tempo, mas ainda sem objetivos delineados. Portanto, este texto quer posicionar de que é necessário aproveitar a força da transição numerique para colocá-la a serviço da transição ecológica. Aparece ainda uma série de indicadores para o agir do poder público e 4 proposições transversais elencadas para fazer acelerar esta transição: 1) reudire l' empreinte écologique du numerique; 2) utilizer le numerique pour mieux concevoir les politiques écologiques; 3) soutenir l'innovation numerique en faveur de l'ecologie; 4) mobiliser les potencial des données au service de la transition écologique. ${ }^{5}$

Num dos itens introdutórios deste texto há a seguinte afirmação de que: “intrinsecamente o numerique não é nem bom nem mal”. Em outro ponto é utilizada a expressão de que não se pode ter uma visão otimista da tecnologia, nem uma abordagem de tecnofobia. Porém, acredito ser necessário complexificarmos neste ponto, pois se intrinsecamente o numerique não é nem bom nem mal, suas consequências o são. Acontece que é difícil compreender ou mensurar de antemão o alcance de tais consequências antes de sua efetivação na prática, o que podemos fazer, no entanto, é projetar modelos ou acompanhar com pesquisas sobre como esta transição está se dando nos mais diversos campos, como o político e sociológico.

Como exemplo, se brevemente fizermos uma observação deste período de crise sanitária que de uma ou outra maneira se entrelaça com outras crises já destacadas aqui, provocadas pelo Covid-19, podemos notar que as redes do numerique só se fortalecem durante este atual período. Como é o caso do trabalho remoto, feito de casa por aqueles que o podem fazer, fez acelerar o uso do numerique. As compras digitais ${ }^{6}$, de serviços, de produtos, de alimentação, de informação, de conteúdo, etc, também contribuem para este acelerar do uso das redes, plataformas e aplicativos. Um novo formato de comércio se intensifica no meio de tudo isso, o capitalismo em sua versão hi-tech.

\footnotetext{
${ }^{5}$ Em tradução livre teríamos o seguinte: (1) reduzir a pegada ecológica da tecnologia digital; (2) utilizar a tecnologia digital para melhor conceber políticas ecológicas; (3) apoiar a inovação digital para a ecologia; e (4) mobilizar o potencial dos dados para a transição ecológica.

${ }^{6}$ Aplicativos de entrega de comida anunciaram em suas páginas oficiais que aumentaram seu movimento em cerca de $30 \%$ no Brasil durante o período da Covid-19, ao mesmo tempo em que se posicionam na justiça pelo não pagamento de seguridade social aos trabalhadores caso estes venham a ser afetados pelo vírus. Na França, jornal Libération de 17 de abril de 2020 traz em sua capa a foto de Jeff Bezos, fundador e presidente da Amazon, que em questão de um mês viu a cotação de sua empresa aumentar 33\%, num período em que há uma grande quebra em vários setores econômicos em todo mundo.
} 


\section{A Aceleração Tecnológica e as Injustiças Ambientais}

Aqui é preciso pontuar as consequências conturbadas do processo de aceleração tecnológica. Como lembra o escritor uruguaio Eduardo Galeano em As veias abertas da América Latina desde a primeira versão de seu livro em 1978, "a deusa tecnologia não fala espanhol". Com isso ele quer nos provocar de que a tecnologia não participa da linguagem (ou do discurso) da maioria dos habitantes latinos, mesmo que ele refira-se a língua do colonizador espanhol falada por grande parte da população na América Latina, a tecnologia transvestida como uma promessa redentora ao ser tratada como deusa, não preocupa-se com as reais urgências dos povos subalternizados, que falam não só o espanhol, mas o português, o francês e as línguas dos mais variados povos originários dessa região, como o tupi, o guarani, o aimara, o quechua e outras tantas, que só no Brasil estima-se serem cerca de 180.

O mero transplante da tecnologia dos países adiantados, não só implica a subordinação econômica, como também - após quatro séculos e meio de experiência na multiplicação de um oásis de modernismo importado em meio aos desertos do atraso e da ignorância - pode-se afirmar que não resolve problema algum do subdesenvolvimento (GALEANO, 2015, p.344).

Diferentemente dos anos de 1970 em que Galeano pontua essas observações, hoje a tecnologia penetra nas relações cotidianas da grande maioria dos indivíduos, através dos mais variados serviços de aplicativo, redes sociais e plataformas e não mais apenas como uma relação distante realizada por grandes corporações. Embora as grandes corporações continuem presentes e bem fortes, agora o indivíduo também atua no manuseio tecnológico na ponta de seus dedos, fazendo jus a etimologia da palavra digital. É preciso urgentemente pensar sobre as novas relações de trabalho que daí surgem e sua eventual mudança nos direitos trabalhistas, nas novas formas de exploração, desigualdades e injustiças que tocam a vida humana, e se ferem a vida humana também são preocupações concernentes à Educação Ambiental. Se a transição ecológica é um processo que terá de vir mais cedo ou mais tarde, seja ele puxado ou não pela aceleração do numerique, como garantir que esta transição seja justa e não causadora de mais desigualdades? Talvez essa visão de ecologia posta em textos como o do Livre Blanc anteriormente citado, às vezes soa como demasiado separado do ser humano, e de toda relação que se dá no social, que é também cultural, e que trata o aspecto da formação humana na sua esfera individual e coletiva. Por isso a Educação Ambiental aponta para a terminologia socioambiental. 
Outro ponto que gostaria de destacar é o da visão da tecnologia enquanto deusa no texto de Galeano. O deus ex machina dos antigos gregos, em que um recurso teatral de um deus surgido da máquina aparece milagrosamente para solucionar questões até então insolúveis vividas pelos personagens da tragédia. É possível enxergar a expressão grega de alguma forma presente na crença de que ao acelerarmos o numerique, aceleramos a transição ecológica. Como que se esperasse que um advento maior que nós, mais potente que nós, ou exterior a nós, ciente de coisas que não sabemos, possa solucionar os impasses ecológicos anteriores, que estão bem presentes na realidade imediata da concretude da vida.

Esse exercício de desmistificação da tecnologia enquanto salvadora é interessante no sentido de que ele nos faz lembrar que a tecnologia não é algo aparte da sociedade, mas com ela se fez e se faz. Também nos serve como alerta sobre os perigos da mesma e sobre os seus resíduos poluentes e que nem sempre são devidamente discutidos e visibilizados no ambiente democrático, ao contrário são escondidos ou minimizados. A partir disso, a ideia de uma transição ecológica, deveria estar associada a uma preocupação por uma transição justa, em que os resíduos poluentes de uma aceleração tecnológica não significasse jogar esses resíduos no “quintal dos mais pobres" (ACSELRAD, 2009). São inúmeros os exemplos espalhados pelo mundo em que grandes empreendimentos que demandam alto uso tecnológico, costumam estrategicamente transferir a comunidades periféricas os seus riscos sociais e ambientais.

Talvez esta visão, a do não reconhecimento da diversidade cultural, esteja de alguma forma enraizada em nossa constituição moderna, herdeira de um pensamento que nos ensinou sobre a objetividade separadora e redutora ao tratar natureza em separado do ser humano, o objeto separado do sujeito. Porém é preciso fazer esse esforço por rearticular saberes e culturas, como o exercício de reconectar o social com o ambiental.

\section{Desafio da Cultura numerique}

De acordo Bruno Bachimont (2014) temos questões de cultura que são colocadas pelos desafios do numerique. Há para o autor, uma possibilidade posta que é a de mecanizar dados da cultura, sem a mediação interpretativa e a sua objetificação acaba por se constituir em um objeto manipulável. Surge assim uma de suas consequências paradoxais, a de que seus conteúdos podem se produzir e se transformar de maneira automatizada no mundo da virtualidade, uma vez que tudo é operado pela máquina, ou seja, sem a manipulação humana. Desse fato, o conteúdo passa a não ser mais uma expressão cultural a ser analisada, mas um fato a ser analisado. Novamente o fortalecimento da objetividade em detrimento ao subjetivo. 
A objetividade do informacional no mundo das tecnologias da informação, pode nos conduzir a análises estatísticas em maior ou menor grau relevantes para estudos que se queiram objetivos. Ao considerar a importância das análises objetivas em inúmeros campos do conhecimento, compreendo, no entanto, que seja de suma importância a manutenção da dimensão humana neste domínio, para tratar da reinserção do sujeito no mundo da máquina automática, justamente para que o aspecto interpretativo seja regenerado pelo diálogo e pela crítica. Pois, se a objetificação do conteúdo se perpetua, a informação já chega asséptica, tratada pelo jogo dos algoritmos das redes. Assim o papel do sujeito se limitaria a mera reprodução automática dos cliques de likes e dislikes.

Para Bachimont (2014) temos alguns problemas que surgem dessa nominalização da cultura. O primeiro deles é da ordem epistemológica e o segundo de ordem fenomenológica. Ele se questiona em que medida o tratamento efetuado em cima dos dados permite uma análise científica do real cultural? E ainda fala que ao retirarmos os dados do seu regime ordinário de interpretação, a gente acaba por retirar o terreno cultural onde estes dados fazem sentido.

Neste sentido, acredito que a Educação Ambiental nos convidaria a refletir acerca da força pedagógica mobilizadora da reflexão crítica ao se tratar questões de cunho socioambiental das sociedades de rede sem sermos meros transmissores dessa informação, mas partícipes, autores e responsáveis desses conteúdos. Como nos lembra o educador Paulo Freire, a objetividade sem subjetividade é mecanicista, e a subjetividade sem objetividade é subjetivismo.

O fato de me perceber no mundo, com o mundo e com os outros me põe numa posição em face do mundo que não é a de quem nada tem a ver com ele. Afinal, minha presença no mundo não é a de quem nele se adapta, mas a de quem nele se insere. É a posição de quem luta para não ser apenas objeto, mas sujeito também da história (FREIRE, 2018, p.53).

Ensinar, em sua dialógica do aprender e ensinar, nos exige a capacidade de apreender sobre a realidade, não como uma forma de mera adaptabilidade à realidade, mas como uma forma especialmente de transformá-la. Neste caso, a realidade da sociedade em rede, interconectada é sem dúvida um desafio premente de nosso tempo, que nos exige esse esforço por compreensão sobre seus mecanismos, discursos e operabilidades. Frente às novas tecnologias é preciso manter o questionamento presente de como integrá-las na prática educativa como valores pedagógicos instauradores de novas relações aprendentes, impregnadas de solidariedade, e que contribuam no processo de construção de compreensões transformadoras nos diversos ambientes da sociedade. Porque "as tecnologias digitais como, 
ademais, qualquer tecnologia, precisam vir acompanhadas de vigilância crítica sobre o seu significado e alcance" (ADAMS; STRECK, 2010, p. 125).

A tecnologia está mudando a nossa maneira de viver juntos, de nos comunicar, interagir e aprender. Podemos dizer que está mudando a cultura, pois o numerique se insere na cultura, como a cultura se insere no numerique e isso modifica também os modos de organização societária e os modos da organização de uma cultura democrática. Assim, vamos vendo que inúmeros termos vão se conectando, como o de ambiente, sociedade, tecnologia, educação, cultura, democracia. Um anel interligado por fenômenos que precisam ser estudados em separado e juntos ao mesmo tempo.

\section{Para Concluirmos}

Ao retomarmos o início da discussão a partir da inspiração de Thoreau, lembramos que o gesto dele em Walden era o de voltar-se para o essencial da vida, que para ele era encontrado na simplicidade. Na cabana, solitário, com pouca interação social, era na meditação dos pequenos detalhes do cotidiano que ele encontrava a riqueza em ser e do vir a ser. Hoje, isolados em nossas cabanas dos anos de 2020 devido ao isolamento social e ao confinamento feitos para o enfrentamento do Covid-19, a interação social aumentou nos espaços virtuais e já não nos imaginamos se quer um dia sem o apoio tecnológico que nos conecta aos outros e ao mundo inteiro, para a realização das mais diversas atividades. Será que a tecnologia passou a ter este atributo de ser essencial em nossa vida cotidiana contemporânea? $\mathrm{O}$ acesso as tecnologias digitais é igualmente garantido a todos? Como a Educação ambiental pode nos auxiliar a pensar a relação sociedade, tecnologia e ambiente?

As dúvidas são muitas, mas é preciso começar por duvidar das dúvidas e tratar de religar com rigor e criticidade, conhecimentos que por ventura possam estar auto centrados em suas ilhas de certezas. Isso é um dos desafios impostos por essa aceleração tecnológica e estimulados a pôr em marcha por uma metodologia transdisciplinar e pensamento complexo.

Após as discussões aqui expostas, podemos compreender que não há uma unidirecionalidade dos discursos sobre tecnologia. A tecnologia e seus discursos, bem como a aceleração numerique possuem interesses diversos e por vezes divergentes. $\mathrm{O}$ desafio educativo de uma Educação Ambiental neste sentido está em como promover sujeitos aprendentes voltados a uma preocupação socioambiental neste terreno tão incerto do tecnológico e tão promotor de injustiças e ainda concomitante a isto instigar uma formação cidadã e democrática, quando por vezes a própria democracia carece de críticas porque ela própria corre grandes 
perigos nestes novos desenhos da sociedade em rede. Mais do que estimular uma alfabetização numerique ou do digital em vias de instrumentalizar o sujeito para sua ação individual e para uma mera adaptação do sujeito ao ambiente tecnológico, a Educação Ambiental, enquanto campo que traz fortemente marcado a preocupação com os aspectos socioambientais, nos convida a reflexão para uma um protagonismo desses sujeitos nesses espaços e para uma alfabetização, quem sabe, para além do digital, que seja promotora de uma alfabetização humana, ecológica, solidária e que seja questionadora dos modos de ser e pensar desses tempos de aceleração tecnológica.

\section{Referências}

ACSELRAD, Henri. O que é justiça ambiental. Rio de Janeiro: Garamond, 2009.

ADAMS, Telmo; STRECK, Danilo. Educação popular e novas tecnologias. Revista Educação, Porto Alegre, v 33, n.2, p 119-127, 2010.

BACHIMONT, Bruno. Le nominalisme et la culture: questions posées par lês enjeux du numérique. In: STIEGLER, Bernard (org.). Digital studies: organealogie des savoirs et technologies de la conaissance. FYP éditions France, 2014.

CARVALHO, Isabel Cristina de Moura Carvalho. Educação Ambiental: a formação do sujeito ecológico. São Paulo: Cortez, 2012.

FREIRE, Paulo. Pedagogia da Autonomia: saberes necessários à pratica educativa. São Paulo: Paz e Terra, 2018.

GALEANO, Eduardo. As veias abertas da América Latina. Porto Alegre: L\&PM,2015.

HANNIGAN, John. Sociologia Ambiental. Petrópolis: Editora Vozes, 2009.

LOUREIRO, Carlos. Trajetórias e fundamentos da Educação Ambiental. São Paulo: Cortez, 2009.

MORIN, Edgar. Ensinar a viver: manifesto para mudar a educação. Porto Alegre: Sulina, 2015.

MORIN, Edgar. O método 1: a natureza da natureza. Porto Alegre: Sulina, 2016.

MORIN, Edgar. Entrevista feita por Simon Blin. Jornal francês Libération em 27 de março de 2020. Original disponível em: https://www.liberation.fr/debats/2020/03/27/edgar-morinressentir-plus-que-jamais-la-communaute-de-destins-de-toute-1-humanite_1783400 . Tradução para a língua portuguesa feita por Samuel Lopes Pinheiro e veiculada no site OBSERVARE: https://observatorioea.blogspot.com/2020/03/morin-sentir-mais-do-quenunca.html 
NICOLESCU, Basarab. Transdisciplinaridade: um esperança para a humanidade. In:

DRAVET, Florence; PASQUIER, Florent; COLLADO, Javier; CASTRO, Gustavo

(Orgs.).Transdisciplinaridade e educação do futuro. Brasília: Universidade Católica de Brasília, 2019.

THOREAU, Henry. Walden. Porto Alegre: L\&PM, 2018.

THOREAU, Henry. La désobéissance civile. Barcelona: Le mot et le reste, 2018. 